\title{
FASILITAS KEBUGARAN DENGAN PENGALAMAN GYM VIRTUAL
}

\author{
Jessica Luckminto ${ }^{1)}$, Tatang H. Pangestu ${ }^{2)}$ \\ 1)Program Studi S1 Arsitektur, Fakultas Teknik, Universitas Tarumanagara, jessicaluckminto@live.com \\ 2) Program Studi S1 Arsitektur, Fakultas Teknik, Universitas Tarumanagara, tatang_pangestu@hotmail.com
}

\begin{abstract}
Abstrak
Jakarta memiliki tingkat ekonomi yang tinggi dan terus meningkat. Generasi millennial sebagai masyarakat usia produktif bekerja mulai merasa stress, tertekan, jenuh, emosi, bahkan depresi akibat persaingan ekonomi dan tuntutan pekerjaan untuk memenuhi kebutuhan hidupnya. Beberapa tindakan pencegahan tingkat stress seseorang dapat dilakukan dengan cara relaksasi diri, rekreasi/ berlibur, melakukan hobi, dan berolahraga. Sayangnya, generasi millennial hanya memiliki sedikit waktu untuk relaksasi dan bersenang-senang. Mereka dihadapkan pada gaya hidup yang sibuk, sehingga mengabaikan kesehatan dirinya, termasuk aktivitas fisik dan kecukupan asupan nutrisi. Dengan adanya kemajuan teknologi, seperti virtual reality tidak hanya sekedar dimanfaatkan dalam dunia hiburan, pendidikan, dan penelitian. Virtual reality ini dapat diterapkan dalam gym, menjadi suatu kegiatan olahraga yang menyenangkan, menantang, dan adiktif. Gym yang dilakukan akan terasa seperti bermain games, seolah-olah berada di dunia penuh imajinasi, padahal secara tidak langsung mereka sudah membakar kalori saat aktif bergerak, sehingga membuat sehat dan bugar. Hal ini tentunya memberi pengalaman baru bagi generasi millennial yang bersifat suka mencoba sesuatu yang baru, mengikuti tren, dan teknologi. Sehingga munculah proyek Fasilitas Kebugaran dengan Pengalaman Gym Virtual. Tujuan proyek untuk meningkatkan kualitas hidup masyarakat untuk tetap menjaga kesehatan dan kebugaran tubuhnya sebagai salah satu cara pencegahan stress di tengah kesibukan tuntutan pekerjaan. Metode desain yang digunakan yaitu tipologi. Selain dalam hal gym, di proyek ini juga dilengkapi fasilitas penunjangnya, seperti food court yang menyediakan makanan-makanan sehat, area-area komunal untuk masyarakat bersosialisasi (jogging \& bicycle track), dan untuk spa, relaksasi, hiburan, hingga retail.
\end{abstract}

Kata kunci: Gym; Kebugaran; Olahraga; Virtual

\begin{abstract}
Jakarta is an ever-growing, high economy city. The generation of millenials as its productive workforce tends to experience stress, pressure, boredom, and even depression due to competition and fulfilling demands. A few measures of prevention against individual's rising stress level may be done by self-relaxation, recreation, hobby, and exercising. Unfortunately, millenials have little to no time to relax and enjoy themselves. They are faced with strenuous lifestyle at the expense of their own health, which include the lack of physical activities and balanced nutrition. Some millenials had become aware of the importance to living healthy and obsessed themselves with a proper lifestyle. While some others still hold onto the perception that exercising is difficult, time-wasting, and boring. With the advance of technology like virtual reality, as not only being used in entertainment, research and education, it is applied in gyms to provide a fun and thrilling exercise. Exercising felt like playing games inside a virtual world, while still burning calories. This creates a new scope of experience to millenials who tend to seek something new, technological, and trend-following. Fitness Center with Virtual Gym Experience implements virtual reality technology as its trademark, and as opposed to conventional gyms. This project aims to elevate the lifestyle quality of community as means of stress-prevention against working demands. The method of design applied is typology. Other than gym, several supporting facilities are present such as food court, communal areas, jogging \& cycling track, spa, and retail.
\end{abstract}

Keywords: Fitness; Gym; Sports; Virtual 


\section{PENDAHULUAN}

Generasi $Y$ atau yang dikenal dengan generasi millennial merupakan sekelompok orang yang lahir antara tahun 1980 - 2000. Sebagai "digital natives", mereka sudah mengenal teknologi sejak kecil dan mengikuti perkembangannya hingga saat ini. Ketertarikan mereka terhadap teknologi membantu kehidupannya, misalnya dalam hal kesehatan, mau mencurahkan waktu dan uangnya untuk berolahraga dan makan sehat. Mereka juga memiliki rasa keingintahuan yang tinggi serta suka mencoba pengalaman baru.

Berdasarkan Badan Pusat Statistik (BPS), generasi millennial yang tengah berada di usia produktif ini memiliki jumlah populasi terbesar dibandingkan generasi lainnya, termasuk di DKI Jakarta. Jumlah mereka (kelompok usia 25-39 tahun) mencapai 2,97 juta jiwa atau sekitar $28 \%$ dari 10,47 juta jiwa total populasi penduduk DKI Jakarta. Sehingga generasi millennial memiliki signifikan yang besar dan dapat membawa perubahan terhadap dunia, termasuk pada tipologi lingkung bangun.

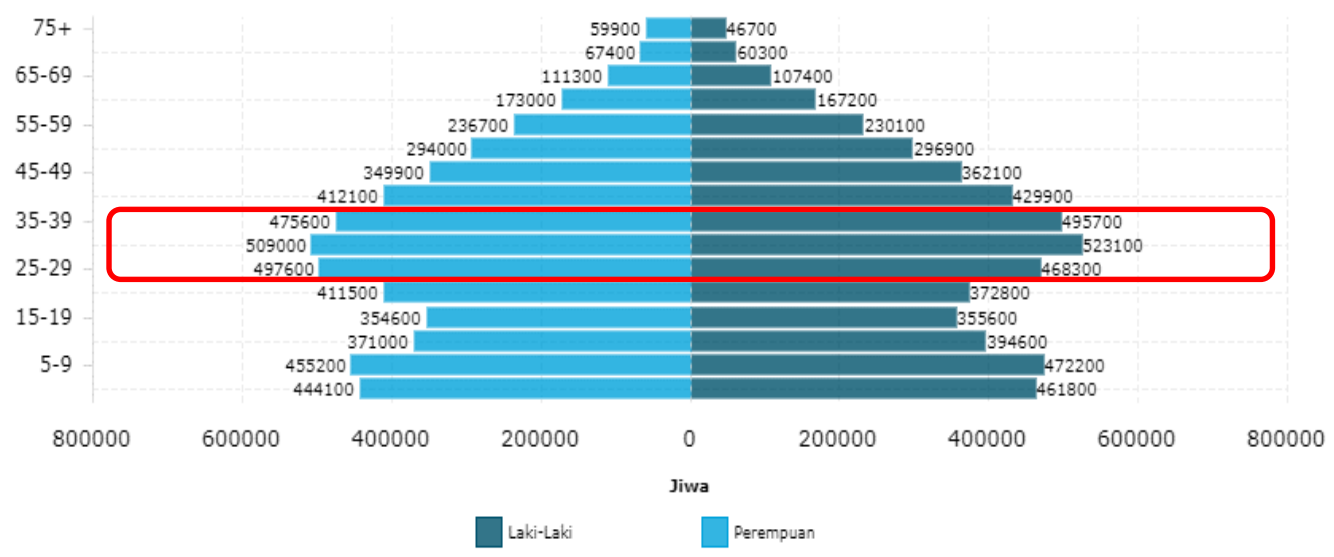

Gambar 1. Jumlah Penduduk DKI Jakarta menurut Kelompok Umur dan Jenis Kelamin Sumber: databoks.katadata.co.id

Sebagai salah satu kota terpadat di Indonesia, Jakarta memiliki tingkat ekonomi yang tinggi dan terus meningkat. Generasi millennial sebagai masyarakat usia produktif bekerja ini pun mulai merasa stress, tertekan, jenuh, emosi, bahkan depresi akibat persaingan ekonomi dan tuntutan pekerjaan untuk memenuhi kebutuhan hidupnya. Menurut American Psychological Association, generasi millennial merupakan generasi dengan tingkat stress tertinggi. Hampir $40 \%$ kaum millennial mengalami peningkatan stress dari tahun sebelumnya. Menurut seorang psikolog, Kartasasmita, M. Psi, pekerjaan merupakan penyebab stress tertinggi pada seseorang.

Saat ini penanganan stress hanya dilakukan melalui tahapan medis, dimana penderita sudah terlanjur mengalami gangguan kejiwaan. Padahal sebelum penanganan, dapat dilakukan tindakan pencegahan untuk menurunkan tingkat stress seseorang. Misalnya dengan relaksasi diri, rekreasi/ berlibur, melakukan hobi, dan berolahraga. Sayangnya, generasi millennial dihadapkan pada gaya hidup yang sibuk, sehingga mengabaikan kesehatan dirinya, termasuk aktivitas fisik dan kecukupan asupan nutrisi. Jadwal kegiatan yang padat membuat mereka menyukai segala sesuatu yang instan, mudah, dan cepat, misalnya terbiasa mengkonsumsi makanan cepat saji.

Akibatnya, terjadi perubahan pola gaya hidup yang sebelumnya lebih banyak beraktivitas di luar rumah menjadi malas atau kurang bergerak karena semua bisa dilakukan dengan mudah. Mereka juga jadi jarang atau bahkan tidak ada waktu untuk berolahraga. Di seluruh dunia, 31,1\% orang dewasa secara fisik tidak aktif (Pedro C. Hallal, 2012). Penurunan aktivitas fisik mengakibatkan peningkatan besar penyakit (obesitas, diabetes, hipertensi, jantung, dan stroke) (James H. O'Keefe, 201) dan gangguan kesehatan mental (Samuel B. Harvey, 2010).

Sebagian generasi millennial sudah sadar akan pentingnya kesehatan sejak dini dan 
terobsesi dengan gaya hidup sehat. Misalnya, mereka mulai meluangkan waktunya untuk gym sebelum ataupun sesudah bekerja. Sedangkan sebagian lainnya, masih memiliki persepsi bahwa akitivitas fisik/ olahraga/ gym ini adalah suatu kegiatan yang meyulitkan, memakan banyak waktu, dan membosankan.

Dengan kemajuan teknologi, seperti virtual reality, tidak hanya sekedar dimanfaatkan dalam dunia hiburan, pendidikan, dan penelitian. Virtual reality ini dapat diterapkan dalam olahraga/ gym. Dimana akan mengubah pandangan/ persepsi seseorang yang menganggap gym/ olahraga membosankan dan sulit, menjadi suatu kegiatan olahraga yang menyenangkan, menantang dan adiktif. Gym yang dilakukan akan terasa seperti bermain games, seolah-olah berada di dunia penuh imajinasi, padahal secara tidak langsung mereka sudah membakar kalori saat aktif bergerak, sehingga membuat sehat dan bugar. Hal ini tentunya memberi pengalaman baru bagi generasi millennial yang bersifat suka mencoba sesuatu yang baru, mengikuti tren, dan teknologi.

Oleh karena itu dibutuhkan sebuah wadah yang dapat meningkatkan kesehatan dan kebugaran masyarakat, mencegah stress, dan relaksasi dari rutinitas serta tuntutan pekerjaan. Adanya teknologi virtual reality menjadi keistimewaan khusus wadah kebugaran ini dibandingkan pusat kebugaran umumnya yang masih menggunakan peralatan gym konvensional. Selain itu, usulan proyek juga harus dilengkapi dengan perencanaan sebuah sarana pengaturan dan penyedia makanan sehat dan praktis di dalamnya, dilengkapi area-area komunal untuk sosialisasi bagi penggunanya, dan ruang terbuka hijau dari segi lingkungan.

Batasan masalah dalam proyek ini, pertama program yang ditawarkan berupa aktivitas untuk kebugaran dan relaksasi yang dapat dilakukan dalam waktu singkat (instan), bukan untuk waktu lama. Serta kegiatan olahraga yang ada hanya untuk relaksasi, menyalurkan hobi, dan tujuan kesehatan, bukan sebagai area latihan dengan standar pertandingan, perlombaan, ataupun olimpiade. Kedua, proyek tetap dapat digunakan oleh seluruh kalangan masyarakat, namun sasaran utama diperuntukan bagi generasi millennial (masyarakat usia produktif bekerja) dengan status ekonomi menengah ke atas. Karena hal ini baru bisa didapatkan ketika kebutuhan primer/ pokok (papan, pangan, dan sandang) seseorang sudah terpenuhi. Ketiga, proyek melayani masyarakat di skala kota atau lingkungan perkotaan.

Rumusan masalah utamanya yaitu, "Bagaimana rancangan arsitektur yang tepat untuk meningkatkan kesehatan dan kebugaran sesuai dengan perilaku masyarakat generasi millennial saat ini?" Sehingga proyek memiliki tujuan utama agar meningkatkan kualitas hidup masyarakat untuk tetap menjaga kesehatan dan kebugaran tubuhnya sebagai salah satu cara pencegahan stress di tengah kesibukan tuntutan pekerjaan. Kondisi masyarakat yang sehat dan bugar dapat meningkatkan produktivitas kerjanya, sehingga berdampak pada pertumbuhan ekonomi kota. Proyek ini juga menerapkan nilai-nilai Sustainable Development Goals terutama untuk poin Good Health and Well-being.

\section{KAJIAN LITERATUR}

\section{Karakteristik Generasi Millennial}

- Berpikiran terbuka (open minded), rasa penasaran tinggi, suka mengekspresikan diri (self-expression), dan toleransi tinggi terhadap sosial (social awareness).

- Bisa melakukan beberapa hal sekaligus/multitasking.

- Cashless/transaksi secara non tunai.

- Gaya hidup yang serba instan, mudah, cepat. Contohnya, makanan cepat saji/ fast food, online shopping.

- Mandiri dan memilih cara belajar yang otodidak, serta self learner.

- Mudah beradaptasi, cerdas, dan cepat.

- Jam kerja yang fleksibel, hingga jam tidur \& makan tidak teratur. 
- Connected/ terhubung internet dan suka berbagi aktivitas sosial (sharing).

\section{Pengertian, Penyebab, dan Penanganan Stress \\ Pengertian Stress}

Stress adalah suatu bentuk ketegangan fisik, psikis, emosi, dan mental, yang dialami oleh seseorang sehingga dapat mempengaruhi kegiatan orang tersebut.

\section{Penyebab Stress}

- Secara internal: rasa pesimisme, ketidakmampuan menerima ketidakpastian, berpikir kaku, kurang fleksibel, berpikir negatif, perfeksionisme.

- Secara eksternal: pekerjaan, hubungan, perekonomian, keluarga, kesibukan.

\section{Metode Penanganan Stress}

Berikut merupakan beberapa metode yang dapat diterapkan untuk menangani stress (Jeanne Segal, 2018):

- Melakukan hobi, dapat menenangkan pikiran, jiwa, dan memulihkan semangat.

- Komunikasi, menceritakan masalah atau beban hidup ke teman, keluarga, atau ahli, dapat mengurangi beban yang dialami.

- Mandi atau berendam, air memiliki efek yang baik dan ampuh untuk menyembuhkan serta menenangkan diri.

- Pijat, untuk relaksasi dan menormalkan kembali tekanan darah. Dengan pijat, hormon penyebab stress dapat berkurang hingga $53 \%$.

- Olahraga, membantu melepas hormon serotonin, membuat seseorang merasa senang.

- Rekreasi/ berlibur, untuk menghindari lingkungan negative ataupun sekedar menjauh dari rutinitas penyebab stress dan membuat perasaan lebih relaks.

- Aromaterapi, mempengaruhi emosi manusia sebab indera penciuman terhubung dengan pusat kendali emosional dalam otak manusia.

- Mendengarkan musik, melepaskan zat endorphin mengurangi stress dan rasa sakit.

- Makanan sehat, yang mengandung vitamin B, omega 3, asam folat, magnesium, dan vitamin $C$ dapat meredakan stress. Makanan yang mengandung antioksidan juga baik untuk dikonsumsi karena mampu memperlancar fungsi memori.

\section{Pusat Kebugaran/Fitness Center}

\section{Tahapan Program Fitness}

Terdapat 5 tahap dasar program umum fitness, yaitu (Mangihot Pasaribu, 2019):

1. Pemanasan (Warm-up)

2. Pembakaran kalori (Aerobic)

3. Kelenturan

4. Pembentukan serta penguatan tubuh secara total

5. Pendinginan

Jenis Latihan pada Fitness

Terdapat 2 jenis latihan pada fitness, yaitu;

1. Latihan beban

Latihan beban menggunakan beban sebagai alat bantu untuk meningkatkan kontraksi otot. Beban yang digunakan bisa beban tubuh sendiri, beban bebas (barbel atau dumbbell), dan beban alat (alat mekanik/ elektronik).

2. Latihan kardio Latihan untuk meningkatkan detak jantung tanpa penggunaan beban.

\section{Macam Kelas Fitness}

Berikut merupakan beberapa kelas fitness dalam berolahraga: 


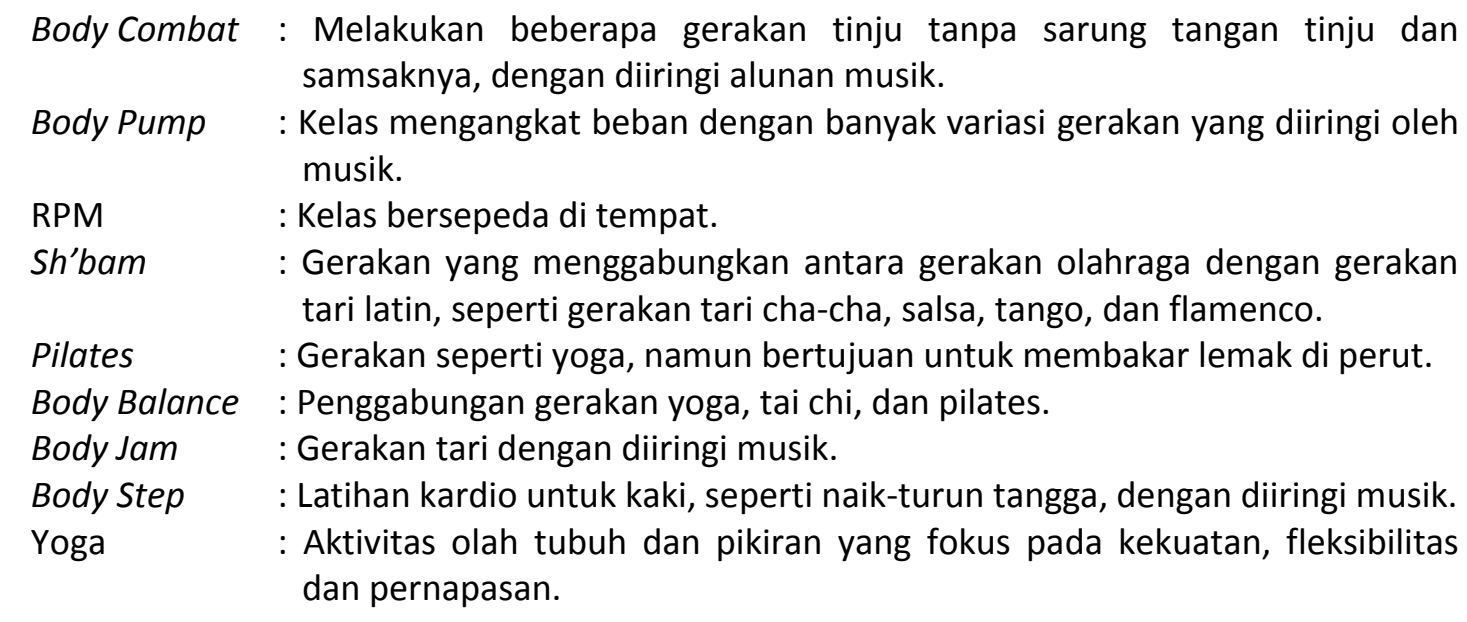

Manfaat Fitness

Beberapa manfaat fitness diantaranya untuk pembakaran lemak, kekuatan fisik, kebugaran, mengurangi risiko penyakit, detoksifikasi, meningkatkan metabolisme, mencegah stress, meningkatkan konsentrasi, melawan pikun di hari tua, membentuk dan mempercantik tubuh, bersosialisasi, menikmati hidup, dan melatih pernafasan.

\section{Ruang pada Fitness Center}

Ruang-ruang yang ada di pusat kebugaran:

1. Fitness space (ruang latihan kebugaran). Mencakup peralatan kardiovaskular, angkat beban, area peregangan/ pemanasan/ pendinginan, lintasan lari indoor.

2. Ruang kelas latihan. Untuk kegiatan kebugaran tertentu, seperti yoga dan aerobik.

3. Ruang loker dan ruang ganti. Dibedakan berdasarkan jenis kelamin untuk berganti pakaian, menyimpan pakaian, mandi, dan toilet. Opsi tambahannya juga terdapat sauna, hot tub, dan area mandi uap.

4. Ruang administrasi dan pendukungnya. Seperti kantor staff, resepsionis, penyimpanan, tempat untuk memperbaiki alat fitness.

5. Ruang tambahannya lainnya untuk meningkatkan pengalaman pelanggan, meningkatkan interaksi sosial dan menyediakan sumber pendapatan, seperti layanan makanan sehat/ jus bar, retail pakaian dan peralatan atletik, penitipan anak, ruang pijat/ terapi fisik, ruang latihan khusus gender, tanning area, ruang pengukuran kebugaran.

6. Kolam renang indoor maupun outdoor. Termasuk kolam lap, kolam keluarga, kolam menyelam, dan kolam air panas.

7. Ruang luar seperti lapangan olahraga, lintasan lari outdoor, dan lintasan sepeda.

\section{Virtual Reality}

Pengertian Virtual Reality

Virtual reality atau realitas maya, merupakan sebuah teknologi yang berisikan simulasi komputer mengenai keadaan suatu lingkungan dan membuat penggunanya seakan-akan dapat berinteraksi dengan lingkungan tersebut. Ketika seseorang melengkapi dirinya dengan berbagai macam peralatan virtual reality, seakan-akan panca inderanya mampu merasakan benar-benar berada dalam lingkungan tersebut, meski jika peralatan dilepas, akan terasa bahwa sebetulnya dunia tersebut hanyalah dunia virtual yang sangat mirip kenyataan. (Hermawan, 2018)

\section{Sejarah Perkembangan Fitness \& Olahraga}

- Pada 500 SM zaman Yunani Kuno, muncul sebuah metode yang berfokus pada pencegahan penyakit daripada hanya mengobati penyakit, dan beranggapan penyakit adalah akibat dari pola makan, gaya hidup, dan faktor lingkungan. Metode ini lebih 
mengutamakan pada kebugaran fisik dengan menyediakan sarana berlatih seperti gymnasium dan lapangan tanding. Jika fisik sempurna, spiritual pun akan sempurna.

- Tahun 1892-an, muncul alat fitness pertama di dunia yang berasal dari era Victoria. Orang yang menemukan dan mengembangkan alat-alat ini adalah seorang dokter orthopedik asal Swedia, Dr. Gustav Zander (Dimas Yulian, 2017).

- Tahun 1965 muncul fitness untuk perumahan.

- Tahun 1983 klub fitness (kebugaran) pertama kali dibuka oleh Mark Mastrovda, Leonard Schlemm, dan rekannya.

- Tahun 2014 berkembangnya teknologi VR dan mulai digabungkan dengan gym.

\section{Tren Olahraga Generasi Millennial}

Berikut merupakan tren olahraga yang paling sering dilakukan oleh masyarakat kota generasi millennial:

1. Marathon. Keterlibatan di event-event lari skala nasional dan internasional, dan menjadi lebih semarak dengan adanya the music run (lari sambal diiringi beberapa genre musik) ataupun the colour run (ada taburan bubuk warna-warni disaat berlari).

2. Pound fit. Olahraga dengan mengikuti irama musik. Sebuah aktivitas olahraga menggebuk dengan menggunakan stick sambil melompat, squat, pilates, serta variasi olahraga lainnya.

3. Yoga. Salah satu jenis yoga yang paling diminat yaitu acroyoga (yoga dilakukan berdua dan dengan gerakan-gerakan akrobatik).

4. Muaythai. Olahraga yang dapat membakar kalori cukup besar (1000 kalori dalam satu sesi latihan 1,5 jam). Muaythai memiliki sesi latihan yang cukup padat, mulai dari pemanasan yang menerapkan pola HIT (high intensity training), sehingga ada banyak otot yang dilatih.

5. Sepeda. Misalnya dengan bersepeda ke kantor, karena kemacetan di kota Jakarta.

\section{METODE}

Diawali dari metode pengumpulan data dengan observasi dan studi dokumen/ literatur. Observasi berupa pengamatan langsung tapak dan lingkungan sekitar di Pantai Indah Kapuk (PIK). Sementara studi dokumen/ literatur untuk mempelajari kajian teori berkaitan tentang kesehatan, kebugaran, stress, fitness, gym, perilaku generasi millennial, tipologi ruang, dan preseden bangunan sejenis. Diambil dari media cetak maupun online.

Dilanjutkan dengan metode analisis data, baik menggunakan data kualitatif maupun data kuantitatif. Untuk data kualitatif, manajemen data diawali dengan riset mengenai perilaku millennial, tipe ruang untuk olahraga/ gym, informasi tapak, kemudian dituangkan menjadi teks atau narasi, transkripsi untuk data selain teks, dan translasi. Lalu reduksi data dengan mengklasifikasi, memusatkan, dan menyederhanakan data pada sesuai tema yang diambil (analisis tematik), yaitu mengenai kesehatan dan kebugaran. Hingga penyajian data berbentuk naratif, grafik, diagram, dan gambar. Sementara untuk data kuantitatif digunakan scoring untuk memilih tapak, dan studi kapasitas pengunjung pada bangunan sejenis.

Terakhir metode perancangan proyek. Tipologi sebagai metode dalam perancangan membantu menerangkan suatu tipe berdasar ciri- ciri atau karakteristik yang dimiliki oleh setiap objek arsitektural. Hal ini menyangkut bangun dasar, sifat dasar, serta proses perkembangan bangun dasar tersebut sampai ke bentuk yang sekarang serta fungsi dari objek. Pada proyek ini penulis mencari tipologinya, lalu dikategorikan dan diklasifikasikan, serta mencari prototipe dan stereotipe dari fitness center. Tipe yang diambil juga turut melihat sejarah/ asal-usul perkembangan fitness center, fungsi utamanya, dan bentuk bangun dan sifat dasarnya. Kemudian dengan pendekatan tipe sebagai ide, fitness center ini dikembangkan dengan menyesuikan perilaku dan kebutuhan generasi millennial. 


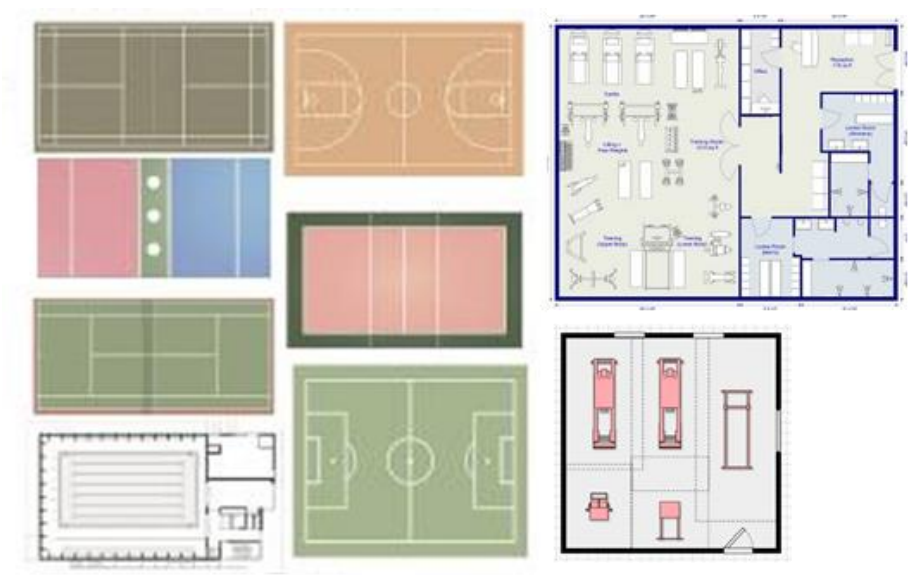

Gambar 2. Tipologi Arena Olahraga

Sumber: google.com

Arena untuk olahraga, gym, dan relaksasi memiliki bentuk dasar persegi panjang. Misalnya bentuk lapangan sepak bola, basket, tennis, hockey, area kolam renang, gym, studio fitness, dan beberapa jenis olahraga lainnya. Hal ini sudah ditetapkan sejak dahulu dan menjadi standar untuk area olahraga hingga saat ini.

\section{DISKUSI DAN HASIL} Kapasitas Proyek

Untuk mengetahui kapasitas proyek yang dibutuhkan, maka penulis terlebih dahulu melakukan studi jumlah pengunjung saat peak hour maupun nonpeak hour pada 3 tempat fitness yang ternama di Jakarta, yaitu Gold's Gym MOI, Celebrity Fitness EX, dan Fitness First Platinum Pasific Place. Berikut perhitungannya.

Tabel 1. Studi Kapasitas Pengunjung

\begin{tabular}{|c|c|c|c|c|c|}
\hline $\begin{array}{l}\text { NAMA } \\
\text { TEMPAT }\end{array}$ & $\begin{array}{l}\text { LUAS } \\
\text { (M2) }\end{array}$ & WAKTU & $\begin{array}{c}\text { JUMLAH } \\
\text { PENGUN } \\
\text {-JUNG }\end{array}$ & $\begin{array}{c}\text { TOTAL } \\
\text { PENGUNJUNG } \\
\text { SAAT PEAK } \\
\text { HOUR }\end{array}$ & $\begin{array}{c}\text { RATA- } \\
\text { RATA } \\
\text { ORANG } \\
\text { GYM 1-3 } \\
\text { JAM }\end{array}$ \\
\hline \multirow{5}{*}{$\begin{array}{c}\text { Gold's } \\
\text { Gym MOI }\end{array}$} & \multirow{5}{*}{1300} & 07.00-10.00 (Peak hour) & 360 & \multirow{5}{*}{1130} & \multirow{5}{*}{376} \\
\hline & & 10.00-12.00 (Non peak hour) & - & & \\
\hline & & 12.00-13.00 (Peak hour) & 250 & & \\
\hline & & 13.00-17.00 (Non peak hour) & - & & \\
\hline & & 17.00-22.00 (Peak hour) & 520 & & \\
\hline \multirow{5}{*}{$\begin{array}{c}\text { Celebrity } \\
\text { Fitness EX }\end{array}$} & \multirow{5}{*}{1000} & 07.00-10.00 (Peak hour) & 315 & \multirow{5}{*}{890} & \multirow{5}{*}{297} \\
\hline & & 10.00-12.00 (Non peak hour) & - & & \\
\hline & & 12.00-13.00 (Peak hour) & 125 & & \\
\hline & & 13.00-17.00 (Non peak hour) & - & & \\
\hline & & 17.00-22.00 (Peak hour) & 450 & & \\
\hline \multirow{5}{*}{$\begin{array}{l}\text { Fitness } \\
\text { First } \\
\text { Platinum } \\
\text { Pasific } \\
\text { Place }\end{array}$} & & 07.00-10.00 (Peak hour) & 230 & \multirow{5}{*}{640} & \multirow{5}{*}{71} \\
\hline & & 10.00-12.00 (Non peak hour) & - & & \\
\hline & & 12.00-13.00 (Peak hour) & 75 & & \\
\hline & & 13.00-17.00 (Non peak hour) & - & & \\
\hline & & 17.00-22.00 (Peak hour) & 335 & & \\
\hline
\end{tabular}

Sumber: Dokumentasi Pribadi, 2019 
Maka rata-rata jumlah pengunjung pada peak hour adalah 376 orang, yang menjadi acuan kapasitas pada proyek.

\section{Analisis Lokasi}

\section{Alasan Pemilihan Tapak}

Sebagai salah satu kota terpadat di Indonesia, Jakarta memiliki tingkat ekonomi tinggi. Hal ini tentu mempengaruhi keberlangsungan hidup masyarakat kota Jakarta, mereka menjadi lebih sibuk bersaing memenuhi kebutuhan hidupnya. Pantai Indah Kapuk (PIK) merupakan kawasan yang diramaikan oleh generasi millennial, tidak jarang orang-orang menyebutnya sebagai pusat gaya hidup generasi millennial. Biasanya orang-orang datang ke PIK bertujuan untuk berkumpul dengan keluarga atau teman dan mencoba berbagai kuliner yang ada (deretan tempat makan mulai dari sekedar kafe sampai restoran kelas atas), atau datang ke pusat perbelanjaan (PIK Avenue), dan hiburan (Waterboom PIK, bazaar, kafe dengan fasilitas game). Mereka datang ke kawasan ini untuk relaksasi dari rutinitas kesibukan pekerjaan sehari-hari. Sehingga kawasan PIK lebih ramai pada saat akhir pekan. Pendatang kawasan ini pun didominasi oleh masyarakat usia produktif, yaitu generasi millennial yang sedang aktif mencoba segala sesuatu yang baru, unik, dan sedang tren.

\section{Analisa Makro dan Meso}

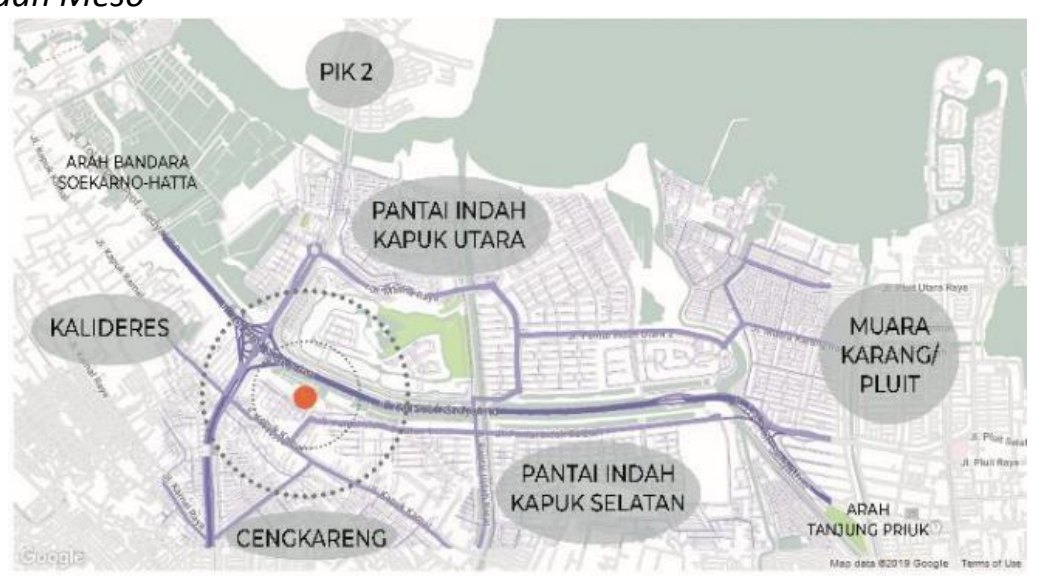

Gambar 3. Peta Kawasan Pantai Indah Kapuk dan Sekitarnya Sumber: dok. pribadi

\section{Kekuatan}

- Aksesibilitas untuk pengguna kendaraan pribadi sangat baik, jalanan yang lebar (14 meter) dan tidak macet karena berada dalam kompleks perdagangan dan perniagaan. Akses masuk tol terdekat melalui Tol Prof. Sedyatmo dan Tol Pelabuhan.

- Kawasan PIK didominasi oleh bangunan ketinggian rendah (hanya 2-4 lantai, kebanyakan perumahan dan ruko komersil), sehingga kualitas udara masih bersih.

- PIK didominasi oleh penduduk maupun pendatang generasi millennial yang menjadi sasaran utama proyek ini.

\section{Kelemahan}

- Aksesibilitas untuk pengguna kendaraan umum dan pejalan kaki kurang memadai. Tidak terdapat halte Transjakarta terdekat, hanya ada Halte Pantai Indah Selatan yang melayani bus umum kota. Namun jaraknya cukup jauh bagi pejalan kaki (500 meter). Dan halte ini tidak ada fisiknya, hanya seketar tempat pemberhentian di pinggir jalan.

\section{Peluang}

- Adanya proyek fasilitas kebugaran ini, diharapkan PIK tidak sekedar terkenal akan gaya 
hidup dan kulinernya yang beragam, tapi juga dapat menjadi icon trademark kesehatan dan kebugaran di Jakarta Utara. Terutama juga karena letaknya yang berada pada zona pelayanan umum dan sosial serta memiliki konektivitas dengan Rumah Sakit Grand Family.

- Penggabungan pusat kebugaran dengan teknologi virtual reality masih sangat jarang ditemukan di Jakarta, apalagi di kawasan PIK. Terobosan baru ini tentunya akan menarik pengunjung khususnya generasi millennial yang mengikuti tren dan gaya hidup tinggi.

- PIK akan semakin ramai pengunjung dari berbagai kawasan lain, mereka dapat menikmati berbagai fasilitas yang lengkap dan berada dalam satu kawasan ini.

\section{Ancaman}

- Sudah banyak pusat kebugaran dan pusat olahraga yang tersebar di Jakarta Utara, termasuk PIK sendiri.

Pemecahan masalahnya adalah dengan menambahkan aktivitas pendukung yang tidak bisa didapatkan di tempat lain. Misalnya dengan memberikan inovasi baru dengan memanfaatkan kemajuan teknologi, yaitu gabungan olahraga/ gym dengan virtual reality, akan memberikan pengalaman baru bagi pengunjung dan berbeda dengan pusat kebugaran pada umumnya.

\section{Analisis Mikro}

\section{Kondisi Tapak}

- Berada di nodes, sehingga mudah ditemukan dan dapat menjadi icon/ penanda bagi bangunan sekitarnya.

- Terletak dekat dengan lingkungan alam. Seperti area biru untuk sungai dan area hijau dengan kondisi bersih, terawat, asri, sehingga dapat menciptakan suasana tenang, relaks, dan nyaman.

- Berada pada jalan sekunder, sehingga menghindari kebisingan yang ditimbulkan lalu lintas pada jalan primer dan memberikan privasi.

- Dekat dengan Rumah Sakit Grand Family, sehingga memudahkan penanganan pengunjung jika terjadi kecelakaan pada saat melakukan aktivitas fisik, ataupun kebutuhan yang bisa didapatkan di klinik rumah sakit.

- Lebar jalanan 12 meter, yang mencukupi untuk kebutuhan untuk 2 lajur mobil pada masing-masing jalur (total 4 lajur), sehingga tidak menimbulkan kemacetan.

- Keamanan yang terjamin karena berada dalam kompleks perdagangan dan perniagaan yang dijaga oleh pos satpam, serta untuk masuk ke area ini harus bayar parkir dengan mesin karcis masuk, sehingga tidak sembarang orang dapat memasuki kawasan ini.

\section{Respon Terhadap Tapak}




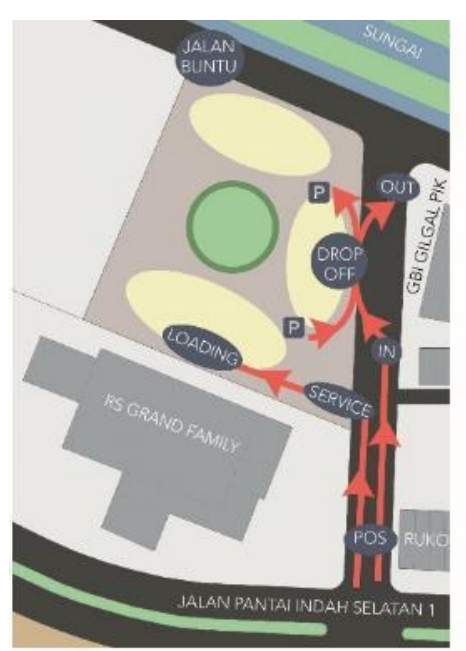

SIRKULASI KENDARAAN

BAGIAN TFNGAH TAPAK SERAGAI PUSAT AKTIVTAS, SOSIALISASI, DAN INTERAKSI. SEHINGGA ORIENTASI \& VIEWBANGUNAN KE DALAM (TENGAH) TAPAKK PEMANFAATAN SUNGAI SEBAGAI VIEW DARI MASSA YANG TERLETAK DEKAT SUNGAL.

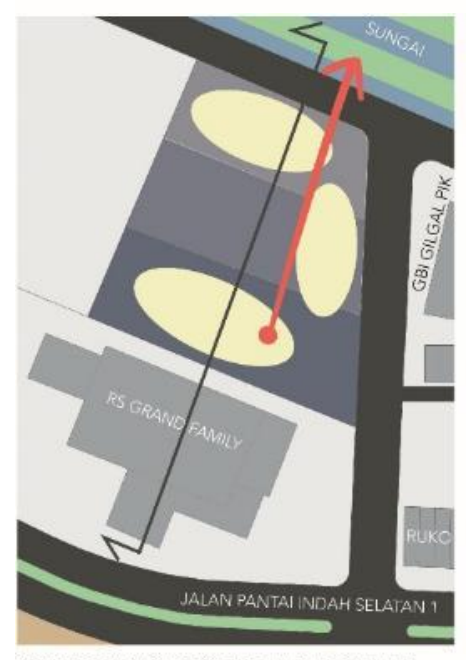

KETINGGIAN \& KEPADATAN BANGUNAN SEMAKIN KE ARAH SUNGAI, BANGUNAN SEMAKI
RENDAH SERTA BERSIFAT RINGAN \& TRANSPARAN). SOSIALISASI, DAN INTERAKSI. SEHINGGA ORIENTASI \&

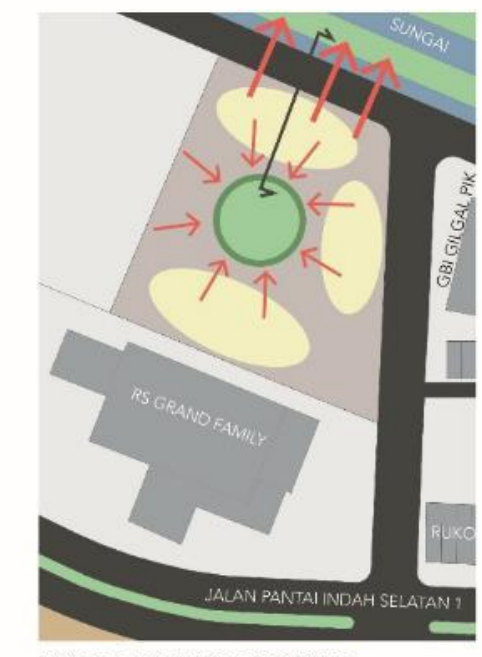

VIEW \& ORIENTASI BANGUNAN BAGIAN TENGAH TAPAK SEBAGAI PUSAT AKTIVITAS VIEWBANGUNAN KE DALAM (TENGAHI TAPAK. EMANFAATAN SUNGAI SEBAGAI VIEW DARI MASSA YANG TERIETAK DEKAT SUNGAI

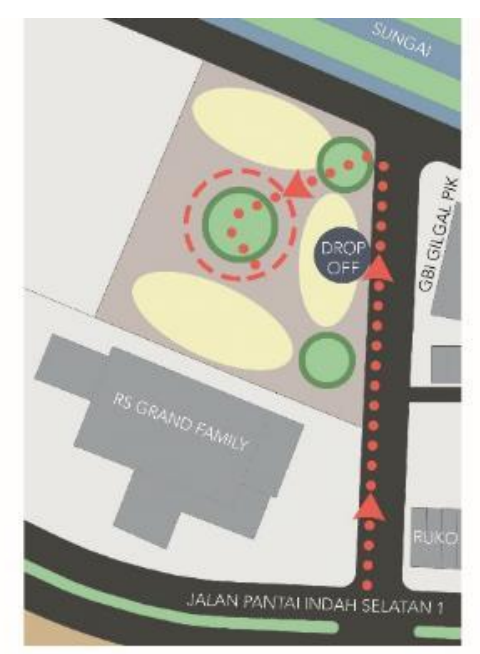

SIRKULASI PEJALAN KAKI \& SEPEDA NODES YANG ADA DAPAT MENIADI AKSES MASUK BAG PEJALAN KAKI MAUPUN SEPEDA. MASSABANGUNAN,

Gambar 4. Respon Terhadap Tapak Sumber: dok. pribadi

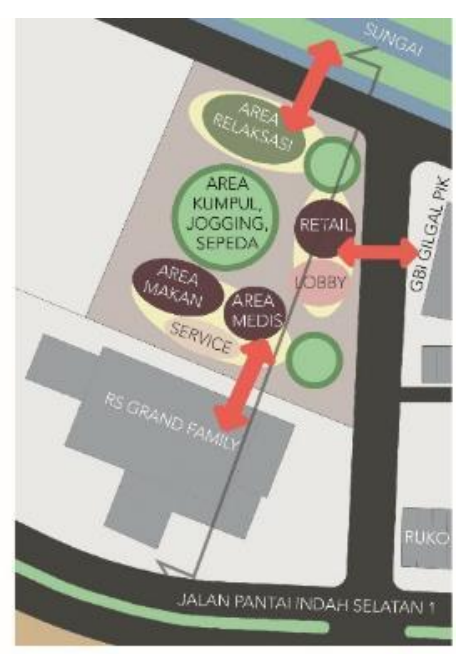

ZONING FUNGSI

AREA PENERIMA TERIETAK DI SEBERANG GERE In GBI GILGAL PIK (LEBIH RAMAI DIBANDINGKAN JALAN BUNTU PADA SISI UTARA

AREA MEDIS TERLETAK DEKAT RUMAH SAKIT GRAND FAMILY (SEBAGAI KESATUAN UINGKUP PELAYANAN). AREA RELAKSASI DILETAKKAN DEKAT DENGAN AREA
HIJAU \& BIRU ISUNGAI).
AREA SERYICE DILETAKAN DI BELAKANG YANG TERSEMBUNYI MEMIUKI KONEKTIVTAS DENGAN AREA MAKAN DAN RETAIL.

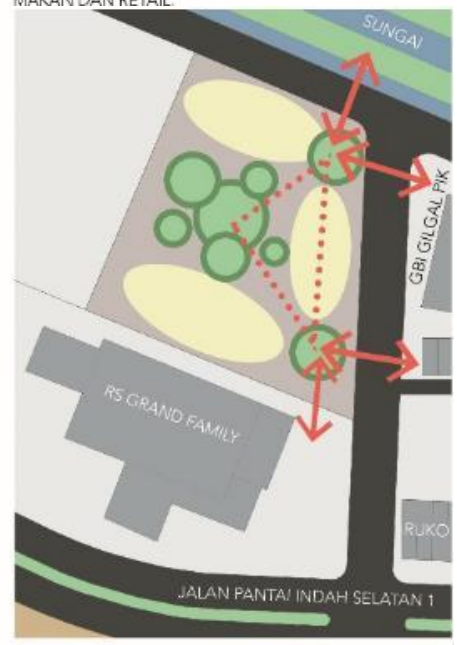

VEGETASI \& R. TERBUKA

BAGIAN TENGAH TAPAK MERUPAKAN PUSAT AKTIVITAS DIBUAT SEGAGAI AREA TERBUKA HIJAU.

AREA NODES MENJADI TITTK KUMPUL ORANG-ORANG DARI UINGKUNGAN SEKITAR (SUNGAI, GEREJA, RUKO DAN RUMAH SAKITI.

\section{Informasi Data Tapak}

Tapak terpilih berada di Jalan Pantai Indah Selatan 1, Kelurahan Kamal Muara, Kecamatan Penjaringan, Jakarta Utara.

Peruntukan : Zona pelayanan umum dan sosial

Luas Tapak : $7824 \mathrm{~m}^{2}$

KDB $\quad: 40$

KLB $\quad: 1,60$

$\mathrm{KB}:: 4$

$\mathrm{KDH}: 35$

Tipe $\quad: 50$

Batasan Tapak:

Utara : Sungai \& area hijau.

PSL : : Kurang Padat

Selatan : RS. Grand Family.

Timur : GBI Gilgal \& ruko.

Barat : Ruko \& pergudangan. 


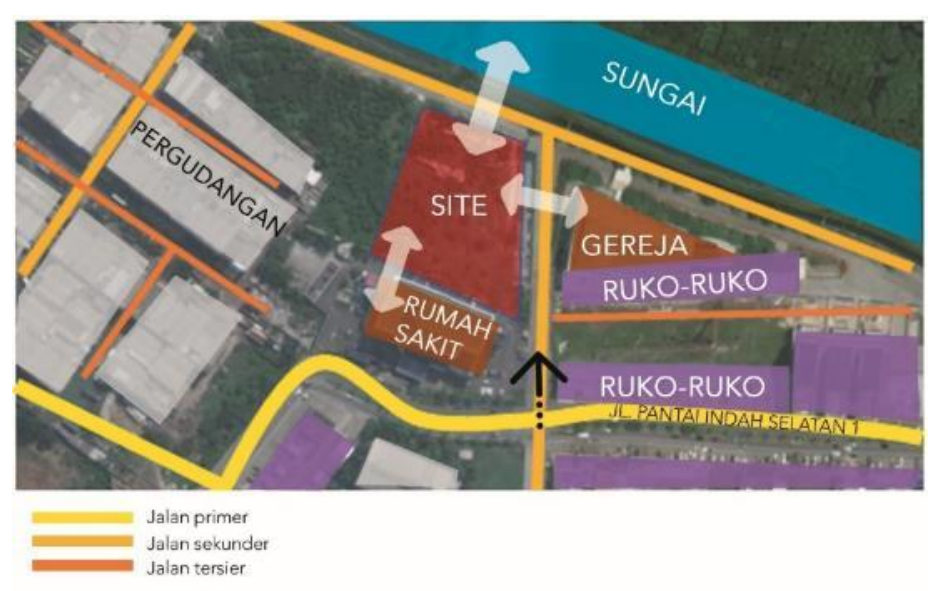

Gambar 5. Lokasi Tapak Terpilih

Sumber: dok. pribadi

\section{Analisis Program Kegiatan}

Program-program pada proyek ini mengacu pada jenis olahraga yang sudah ada, dengan ditambahkan teknologi virtual reality, sehingga menciptakan pengalaman baru. Selain itu, karena hanya dimainkan secara virtual, tidak membutuhkan lapangan yang luas seperti standar bangunan olahraga pada umumnya. Program olahraga yang diterapkan pun mengacu pada tren olahraga yang digemari generasi millennial saat ini dan olahraga gym yang memiliki peraturan sederhana dan mudah untuk dilakukan. Berikut merupakan persentase luasan program beserta ruang penting di dalamnya

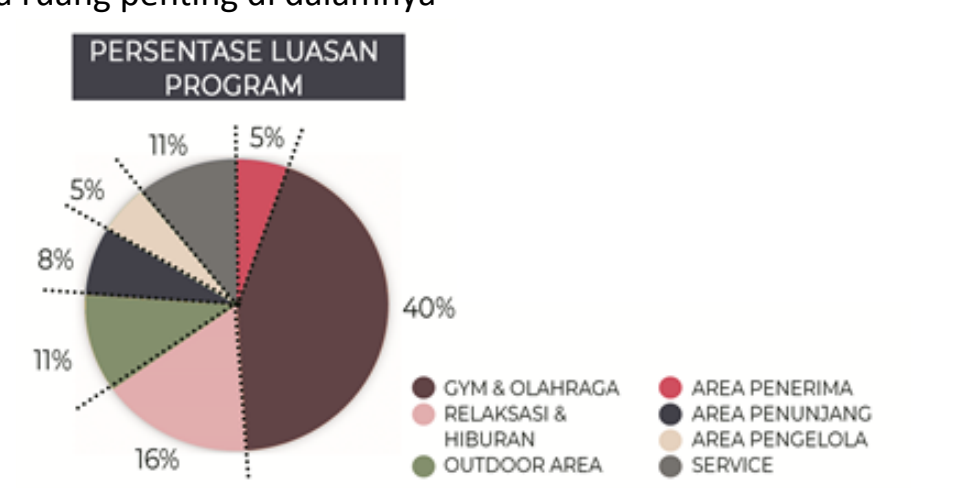

Gambar 6. Diagramatik Persentase Luasan Program Sumber: dok. pribadi

1. Gym \& Olahraga (40\%)

Pada zona ini terdapat berbagai macam area olahraga dan gym, seperti cinematic fitness center (RPM \& cardio), multifunction hall (bentang lebar), cardio area, disc throw arena, paired cardio area, group fitness studio, blackbox gym, freestyle area, wall climbing arena, combat sport arena, dan strength \& free-weight area.

2. Relaksasi \& Hiburan (16\%)

Selain olahraga, proyek juga dilengkapi relaksasi berupa spa, sauna, dan kolam renang. Sementara untuk hiburan terdapat berbagai permainan seperti pingpong, virtual golf, dan billiard.

3. Area Outdoor (11\%)

Selain program yang berada di dalam ruangan, juga diseimbangi oleh kegiatan yang dapat dilakukan dengan memanfaatkan lingkungan alam. Terdapat jogging \& bicycle 
track yang terbuka bagi masyarakat.

4. Area Penerima (5\%)

Pengunjung diterima pada bagian lobby, dan dilengkapi berbagai retail mulai dari sport retail, supermarket makanan sehat, dan health \& beauty retail.

5. Area Penunjang (8\%)

Untuk menunjang program utama, proyek dilengkapi dengan klinik, lounge, food court, dan multifunction room.

6. Area Pengelola (5\%)

7. Servis (11\%)

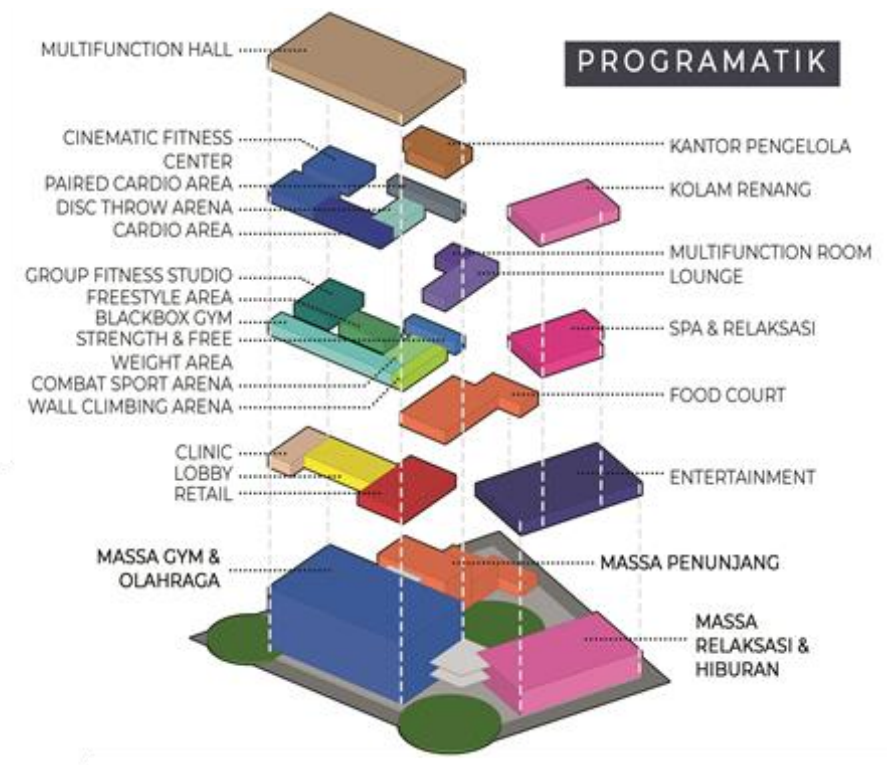

Gambar 7. Diagramatik Program

Sumber: dok. pribadi

\section{Design Scheme}

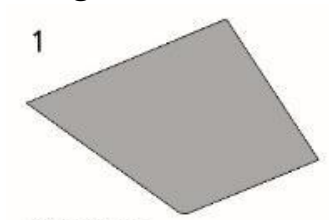

EXISTING SITE

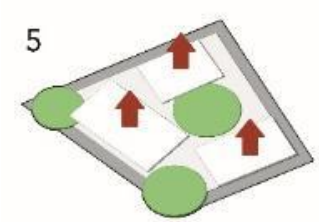

PLLLING UP

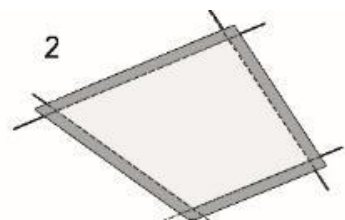

SETBACK FROM SITE

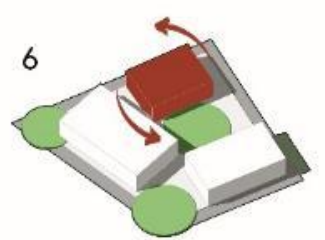

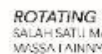

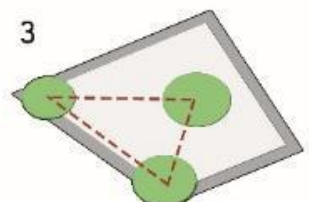

CREATING OPEN SPACES
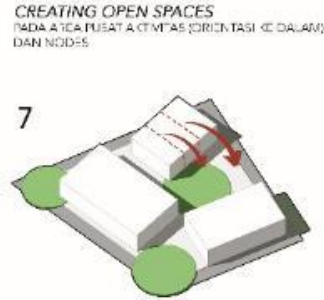

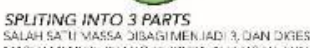

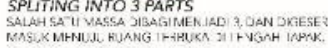
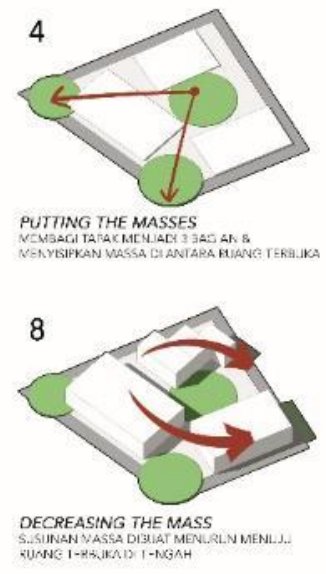

Gambar 8. Design Scheme

Sumber: dok. pribadi

\section{Hasil Bentuk Rancangan}

Dari proses pembentukan massa, penulis menginginkan massa proyek bersifat dinamis. Bentuk massa sendiri dibuat kotak-kotak sesuai dengan metode tipologi arena-arena olahraga. 
Namun agar tidak kaku kotak semua, area outdoor yang berupa jogging \& bicycle track, dibuat dinamis menyelimuti massa-massa yang ada. Sehingga terdapat kesatuan dan konektivitas antara massa yang satu dengan lainnya. Antara massa yang satu dengan lainnya dihubungan oleh teras penghubung. Secara vertikal pun, massa dibuat menurun ke arah plaza di tengah, sehingga terdapat variasi antara massa yang 4 lantai, 3 lantai, 2 lantai, hingga 1 lantai.

Untuk mewadahi program di dalamnya, khususnya area gym \& olahraga, lantai 2 dan 3 nya dibuat menjadi satu kesatuan dengan adanya void yang menerus. Serta lantai 4 paling atas dibuat menjadi area bentang lebar untuk olahraga yang membutuhkan luasan besar.

Terdapat tangga outdoor besar dimana orang-orang dapat duduk-duduk, berinteraksi satu sama lain, dengan view menghadap ke arah sungai. Serta area kolam renang juga dibuat outdoor sehingga memberi kesan ringan.

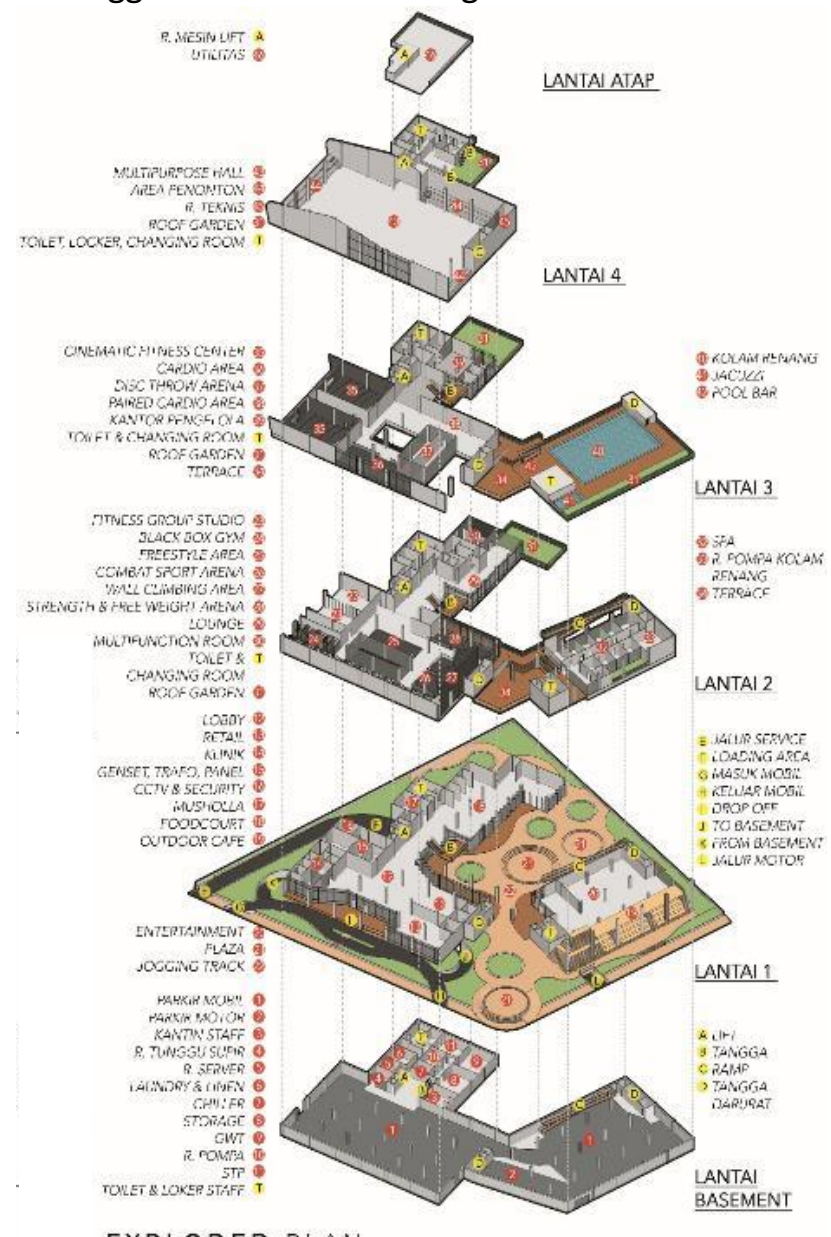

EXPLODED PLAN

Gambar 9. Exploded Denah

Sumber: dok. pribadi

\section{Sirkulasi Bangunan}

Sirkulasi secara vertikal sebagai penghubung antar lantai menggunakan lift, tangga, dan ramp. Di antara massa gym dan olahraga terdapat 1 titik untuk area lift, yang berisi 2 lift pengunjung dan 1 lift servis, serta 1 tangga publik. Sedangkan untuk massa relaksasi dan hiburan menggunakan ramp. Tiap massa memiliki tangga darurat untuk situasi darurat seperti kebakaran. Sedangkan sirkulasi secara horizontal antar massa dihubungkan menggunakan teras dan selasar.

\section{Fasad dan Material Bangunan}


Fasad bangunan banyak menggunakan rangka second skin dengan bahan perforated metal dan curtain wall. Khusus fasad bagian depan, menggunakan lampu led strip dan led screen, yang memberikan kesan futuristik. Atap pada massa gym dan olahraga menggunakan aluminium composite panel dan dibuat melengkung agar dinamis.

\section{Struktur}

Proyek menggunakan struktur beton bertulang untuk kolom, balok, dan plat lantai. Kolom memiliki grid setiap 8 meter (pada bagian tertentu 6 meter). Kolom memiliki ukuran $60 \times 60$ $\mathrm{cm}$ dan $60 \times 80 \mathrm{~cm}$. Sedangkan untuk atap ada menggunakan rangka baja space frame, dak beton, serta roof garden. Berikut merupakan struktur yang digunakan dalam rancangan proyek. Tangga yang digunakan menggunakan material metal.

\section{Suasana Ruang}
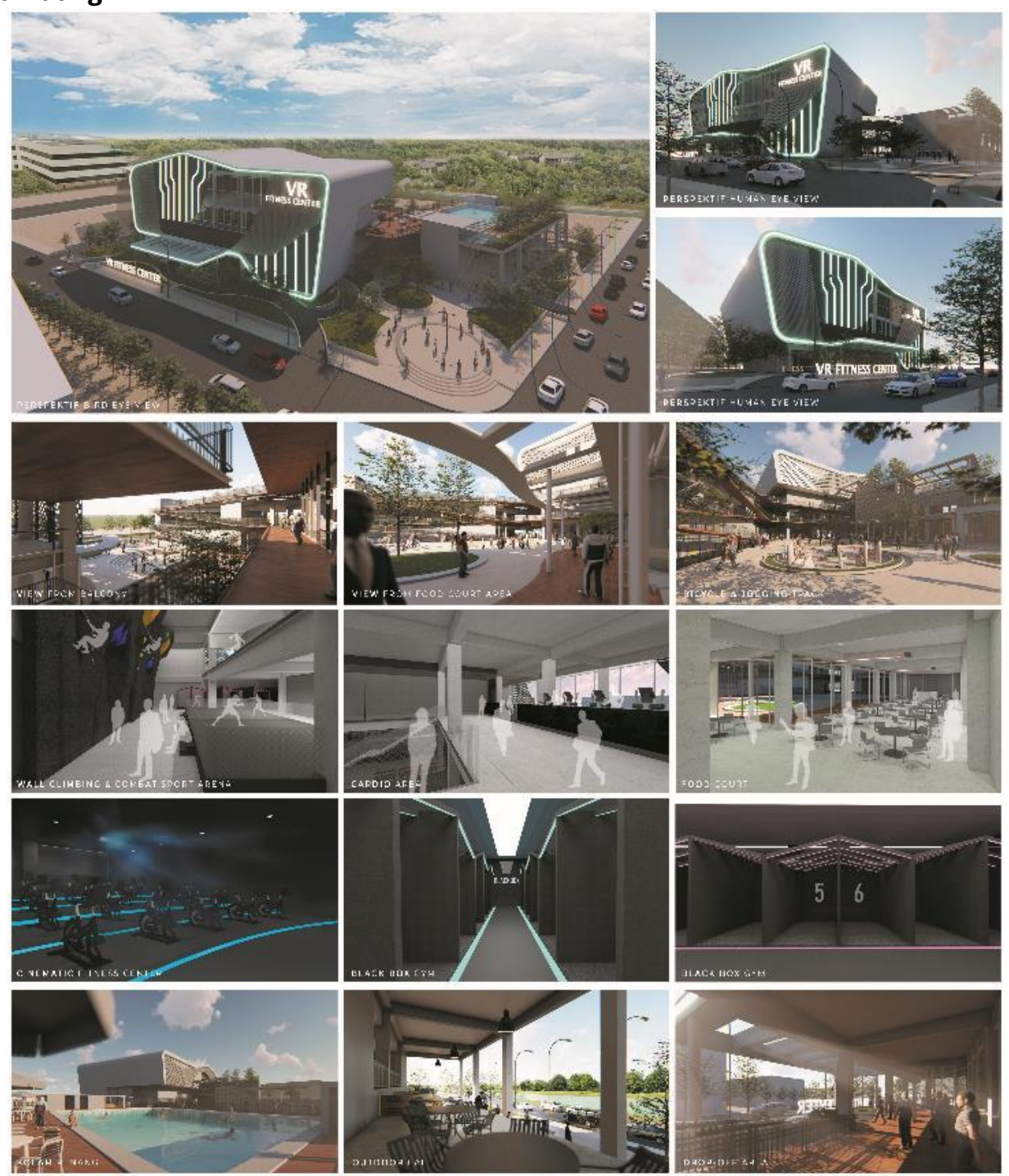

Gambar 10. Fasad Bangunan

Sumber: dok. pribadi 


\section{KESIMPULAN DAN SARAN}

Adanya Fasilitas Kebugaran dengan Pengalaman Gym Virtual ini diharapkan dapat meningkatkan kualitas hidup masyarakat untuk tetap menjaga kesehatan dan kebugaran tubuhnya sebagai salah satu cara pencegahan stress di tengah kesibukan tuntutan pekerjaan, dengan ditambah penerapan teknologi virtual reality yang tentunya akan memberikan pengalaman baru bagi generasi millennial. Selain itu, karena hanya dimainkan secara virtual, tidak membutuhkan lapangan yang luas seperti standar bangunan olahraga pada umumnya. Program olahraga yang diterapkan pun mengacu pada tren olahraga yang digemari generasi millennial saat ini dan olahraga gym yang memiliki peraturan sederhana dan mudah untuk dilakukan. Bentuk massa yang dihasilkan dibuat kotak-kotak dikarenakan dari tipologi arenaarena olahraga yang sudah ada biasanya berbentuk persegi/ persegi panjang dengan area outdoor yang berupa jogging \& bicycle track, dibuat dinamis menyelimuti massa-massa yang ada. Secara vertikal pun, massa dibuat menurun ke arah plaza di tengah, sehingga terdapat variasi antara massa yang 4 lantai, 3 lantai, 2 lantai, hingga 1 lantai. Pada area gym \& olahraga, lantai 2 dan 3 nya dibuat void yang menerus. Lantai 4 dibuat menjadi area bentang lebar. Terdapat tangga outdoor besar dimana orang-orang dapat duduk-duduk, berinteraksi satu sama lain, dengan view menghadap ke arah sungai. Serta area kolam renang outdoor.

Saran penulis sebaiknya proyek fasilitas kebugaran seperti ini semakin dikembangkan mengikuti kemajuan teknologi, sehingga masyarakat khususnya generasi millennial semakin semangat untuk tetap berolahraga, tetap sehat dan bugar, sekaligus mendapatkan pengalaman baru. Selain itu, bangunan ini juga dapat diperbanyak di berbagai daerah, tidak hanya di lokasi saat ini (Pantai Indah Kapuk). Agar jangkauan masyarakatnya lebih banyak.

\section{REFERENSI}

Badan Pusat Statistik. (2018). 71 Persen Penduduk Jakarta Merupakan Usia Produktif. Diakses 15 Januari 2019 dari databoks.katadata.co.id/datapublish/2018/08/01/71-persenpenduduk-jakarta-merupakan-usia-produktif.

Bertisch, S.M., Wells, R.E., Smith, M.T., McCarthy, E.P. (2012). Use of Relaxation Techniques and Complementary and Alternative Medicine by American Adults with Insomnia Symptoms: Results from a National Survery. J Clin Sleep Med, 8(6), 681-691.

England, N. (2009). Childhood and Nature: A Survey on Changing Relationships with Nature Across Generations. Cambridgeshire: Natural England.

Hallal, P.C., Andersen, L.B., Bull, F.C., Guthold, R., Haskell, W., \& Ekelund, U. (2012). Global Physical Activity Levels: Surveillance Progress, Pitfalls, and Prospects, (pp. 247-257). Lancet, Brazil: Universidade Federal de Pelotas.

Harvey, S.B., Hotopf, M., Overland, S., \& Mykletun, A. (2010). Physical Activity and Common Mental Disorders. Institute of Psychiatry Weston Education Centre, 197(5), 357-364.

Hermawan. (2019). Pengertian VR (Virtual Reality) Beserta Sejarah dan Cara Kerjanya. Diakses pada 1 Maret 2019 dari nesabamedia.com/pengertian-vr-virtual-reality/.

Lopez, N. (2017). Gen Y: Millennials in Architecture. Diakses 20 Januari 2019 dari medium.com/studiotmd/gen-y-millennials-in-architecture-476e9839321b.

Nasution, R.J. (2019). Virtual Reality, Cara Kerja, dan Perkembangannya. Diakses pada 5 Maret 2019 dari itgeek.id/virtual-realityvr-cara-kerja-dan-perkembangannya/.

O'Keefe, J.H., Vogel, R., Lavie, C.J., \& Cordain, L. (2010). Achieving Hunter-Gatherer Fitness in the 21st Century: Back to the Future. Kansas City: Mid America Heart Institute/University of Missouri-Kansas City.

Pasaribu, M. (2017). Sejarah Fitness. Diakses 23 Januari 2019 dari mangihot.blogspot.com/2017/02/sejarah-fitness.html.

Roe, M.M. (2019). Pengertian Stress Adalah, Jenis dan Faktor Penyebab Stress. Diakses 20 Januari 2019 dari maxmanroe.com/vid/umum/pengertian-stress.html. 
Segal, J., Smith, M., Segal, R., \& Robinson, L. (2019). Stress Symptoms, Signs, and Causes. Diakses pada 21 Januari 2019 dari helpguide.org/articles/stress/stress-symptoms-signs-andcauses.htm.

Yulian, D. (2017). Inilah Bentuk Peralatan Fitnes Pertama Di Dunia Yang Digunakan Lebih Dari 130 Tahun Lalu. Diakses 14 Februari 2019 dari hai.grid.id/read/07593322/inilah-bentukperalatan-fitnes-pertama-di-dunia-yang-digunakan-lebih-dari-130-tahun-lalu?page=all. 